\title{
Human ESC-derived Neural Rosettes and Neural Stem Cell Progression
}

\author{
Y. ElKabetZ AND L. STUDER \\ Developmental Biology Program, Division of Neurosurgery, \\ Memorial Sloan-Kettering Cancer Center, New York, New York 10065
}

\begin{abstract}
Neural stem cells (NSCs) are defined by their ability to self-renew while retaining differentiation potential toward the three main central nervous system (CNS) lineages: neurons, astrocytes, and oligodendrocytes. A less appreciated fact about isolated NSCs is their narrow repertoire for generating specific neuron types, which are generally limited to a few region-specific subtypes such as GABAergic and glutamatergic neurons. Recent studies in human embryonic stem cells have identified a novel neural stem cell stage at which cells exhibit plasticity toward generating a broad range of neuron types in response to appropriate developmental signals. Such rosette-stage NSCs (R-NSCs) are also distinct from other NSC populations by their specific cytoarchitecture, gene expression, and extrinsic growth requirements. Here, we discuss the properties of R-NSCs within the context of NSC biology and define some of the key questions for future investigation. R-NSCs may represent the first example of a NSC population capable of recreating the full cellular diversity of the developing CNS, with implications for both basic stem cell biology and translational applications in regenerative medicine and drug discovery.
\end{abstract}

The isolation of NSCs from the developing and adult brain has transformed our understanding of CNS development and presented new avenues for regenerative medicine (McKay 1997; Gage 2000). Much effort in the field has been devoted to the identification of factors directing the self-renewal and differentiation of NSCs in vitro and in vivo (Alvarez-Buylla and Lim 2004; Shen et al. 2004; Conti et al. 2005). Such studies demonstrated that single factors act instructively to specify neuronal versus glial fate choice (Johe et al. 1996). However, the ability to direct NSCs toward specific neuronal fates has remained remarkably poor. It is well established that multipotent NSCs from many CNS regions can clonally give rise to neurons, oligodendrocytes, and astrocytes in vitro. However, the neuronal subtype potential of in-vitroexpanded NSCs is largely restricted to GABAergic and, to a lesser extent, glutamatergic fates (Caldwell et al. 2001; Jain et al. 2003). Recent in vivo studies suggest that adult subventricular zone (SVZ) stem cells also exhibit regionspecific biases toward specific neuronal subtypes such as $\mathrm{Pax}^{+} / \mathrm{TH}^{+}$cells or calretinin ${ }^{+} / \mathrm{GABA}^{+}$cells (Merkle et al. 2007). Remarkably, restrictions in neuron subtype potential in the adult SVZ are cell autonomous and retained following extensive in vitro culture (Merkle et al. 2007). These studies suggest that both endogenous NSC populations and NSCs cultured in vitro exhibit developmental and regional bias in neuron subtype differentiation.

In contrast to NSC studies, work with neural plate-stage explants or studies with embryonic stem cells (ESCs) suggest that early neural cells can be specified towards a wide range of neuronal fates. For example, combined exposure to sonic hedgehog $(\mathrm{SHH})$ and retinoic acid (RA) or SHH and FGF8 induces populations enriched in spinal motoneuron $(\mathrm{MN})$ or midbrain dopamine neurons, respectively. These protocols work well in neural-plate-stage explants (Roelink et al. 1995; Ye et al. 1998) and in neural progeny of ESCs (Lee et al. 2000; Wichterle et al. 2002; Barberi et al. 2003) but not in cultured NSCs (Caldwell et al. 2001; Jain et al. 2003). The striking difference in neuron subtype fate potential of ESCs and NSCs suggests that neural patterning response becomes rapidly restricted during neural development. One of the major challenges in NSC biology is therefore the development of novel strategies to enhance the differentiation potential of NSCs. This could be achieved either by manipulating the genetic or epigenetic state of later-stage NSCs or by isolating and maintaining an earlier NSC stage with intact patterning potential.

We have recently reported the isolation of a novel NSC type from human ESCs (hESCs), termed rosette-stage NSCs (R-NSCs) (Elkabetz et al. 2008) based on their characteristic cytoarchitecture. R-NSCs are capable of extensive self-renewal and broad differentiation potential along $\mathrm{CNS}$ and peripheral nervous system (PNS) lineages and readily yield a wide range of neuron types inaccessible to later-stage NSCs (Lee et al. 2007a; Elkabetz et al. 2008). The differentiation potential of R-NSCs corresponds to that of neural-plate-stage cells, and R-NSC-like populations can indeed be isolated directly from neural-plate-stage embryos (Elkabetz et al. 2008). The broad differentiation potential of R-NSCs is reflected by the specific molecular signature and distinct extrinsic growth factor requirements. A major goal of future studies is the identification of the molecular mechanisms that enable broad patterning potential of R-NSCs. In this chapter, we summarize our current understanding of R-NSCs and discuss their properties in the context of ESC and NSC biology.

\section{NEURAL STEM CELLS}

The in vivo persistence of immature neural precursors in the adult rodent brain was first described more than four decades ago (Altman and Das 1965). However, these studies were largely ignored until studies in the 1980 s confirmed a link between dividing precursors in the SVZ and 
postmitotic neuronal progeny in the adult canary brain (Goldman and Nottebohm 1983). Many subsequent studies confirmed and extended these results for both the developing and adult CNS, providing a quantitative description of endogenous murine precursor populations in vivo (Frederiksen and McKay 1988). These early studies revealed strong evidence for the presence of endogenous NSCs in vivo. However, efforts to manipulate NSC fate in a systematic manner required the establishment of relevant in vitro culture systems. Early attempts at isolating and manipulating the fate of neural precursors (Cattaneo and McKay 1990) got a significant boost with the availability of the neurosphere culture technique (Reynolds and Weiss 1992; Kilpatrick and Bartlett 1993; Gritti et al. 1995). Under these conditions, neural precursors are grown as free-floating aggregates on nonadherent plates in the presence of fibroblast growth factor-2 (FGF-2), epidermal growth factor (EGF), or both. For human neurospheres, supplementation with leukemia inhibitory factor (LIF) in addition to EGF and FGF-2 has been proposed (Galli et al. 2000). The demonstration of clonal neurosphere formation, self-renewal, and multilineage potential provided a valuable assay to probe NSC properties in vitro. Neurosphere assays were used for the prospective identification of NSC-like populations from primary tissue based on expression of CD133 (Uchida et al. 2000), SSEA-1 (Capela and Temple 2002), or combinations of positive/ negative marker sets (Rietze et al. 2001). However, neurospheres are composed of heterogeneous cell types including many differentiated cells. Furthermore, in the adult SVZ, proliferating neurospheres are obtained more readily from transient-amplifying cells (type $C$ cells) than from the SVZ stem cell compartment (type B cells) (Doetsch et al. 2002). Therefore, neurosphere data need to be interpreted cautiously, and neither primary nor secondary neurosphere formation is a conclusive assay of NSC identity.

An alternative approach for isolating NSCs in vitro is based on monolayer cultures in the presence of FGF-2 (Davis and Temple 1994; Palmer et al. 1995; Johe et al. 1996). Monolayer techniques allow direct observation of lineage relationships and the establishment of complete lineage trees in vitro (Qian et al. 2000). A recent variation of this technique is the neurosphere (NS) culture system yielding fairly homogeneous populations of radial glial-like NSC progeny in the presence of FGF-2 and EGF (Conti et al. 2005). NS cultures exhibit improved maintenance of neurogenic fate potential following long-term culture and represent one of the few examples of a symmetrically dividing stem cell population (Conti et al. 2005). However, the predominant neuron types generated from NS cells are GABAergic and glutamatergic neurons, similar to the neurosphere and FGF-2-expanded monolayer cultures.

\section{DEVELOPMENTAL POTENCY}

The two key criteria that define NSCs are capacity for extensive self-renewal and multilineage potential toward neurons, astrocytes, and oligodendrocytes (McKay 1997; Gage 2000; Temple 2001). Maintenance of NSCs in vitro or in vivo requires that at least one of the two daughter cells retains NSC potential. In the developing CNS, cells undergo various phases of expansion and differentiation. At the earliest stages of neural development, cells symmetrically expand to yield the precursor pool subsequently generating the broad range of neural cell types. At later stages, cells undergo both asymmetric and symmetric divisions to yield transit-amplifying cells, neurons, and glia. There is evidence that cells at the neural-plate stage contain precursors with plasticity capable of changing anteroposterior (AP) and dorsoventral (DV) identity in response to inducing tissues (Yamada et al. 1993; Hynes et al. 1995) or defined patterning signals (Roelink et al. 1994; Ye et al. 1998). However, it is unclear whether cells at the neural-plate stage represent true NSC populations that undergo many self-renewal divisions before losing patterning potential. Accordingly, the identification of an "authentic" NSC in vivo with the ability to recreate the whole cellular diversity of the CNS has remained controversial (Mukouyama et al. 2006). The situation in the CNS is contrasted by the hematopoietic system, where a single transplanted hematopoietic stem cell (HSC) can successfully reconstitute hematopoiesis throughout the life span of the graft recipient (Morrison et al. 1995).

In the adult brain, there is ample evidence for continuous neurogenesis in specific regions of the CNS, such as in the SVZ along the lateral ventricle (Doetsch et al. 1999) and in the hippocampus (Palmer et al. 1997). However, adult NSC populations display an even more limited neuronal fate potential (Merkle et al. 2007). Although studies in the SVZ have reported broadened differentiation potential toward striatal neuron types upon noggin and BDNF (brain-derived neurotrophic factor) exposure (Chmielnicki et al. 2004), evidence for more general AP or DV respecification of adult NSCs is lacking.

One important question is whether restricted in vivo NSC potential can be overcome following in vitro culture. An expanded differentiation repertoire of isolated "glialrestricted" O2A progenitors toward neuronal fates has been reported after FGF-2 treatment (Kondo and Raff 2000). FGF-2 treatment has also been shown to alter expression of DV markers in neural precursors and to broaden differentiation from bipotent to tripotent fate characteristics in vitro (Gabay et al. 2003). Such studies raise the question of whether in vitro culture and FGF-2 exposure can dysregulate patterning and broaden fate potential. However, FGF-2 has complex roles during development and serves as a patterning factor in its own right (Crossley et al. 1996; Lumsden and Krumlauf 1996; Shimamura and Rubenstein 1997; Shimamura et al. 1997; Bertrand et al. 2000). Therefore, FGF signaling may have roles in both broadening and restricting potential depending on developmental context.

During normal development, there is evidence for regional specification even before neurulation (Quinlan et al. 1995), and early neural-plate cells appear to quickly adopt regional subtype identities (Chang and HemmatiBrivanlou 1998) that impact their ability to respond to patterning morphogenetic cues. A number of studies isolated NSC-like populations from specific regions of the CNS including forebrain (He et al. 2001), midbrain (Ling et al. 1998; Studer et al. 1998), hypothalamus (Markakis et al. 2004), and spinal cord (Mayer-Proschel et al. 1997). These 
studies generally confirm that in-vitro-expanded NSC populations exhibit temporal region-specific neuronal differentiation potential. The issue of whether such restrictions can be overcome in an "instructive" environment remains controversial. Numerous studies have reported remarkable plasticity of grafted neural precursor populations upon heterotopic transplantation in the developing CNS (Brüstle et al. 1995; Campbell et al. 1995; Fishell 1995; Suhonen et al. 1996; Shihabuddin et al. 2000). However, these studies are limited largely to the analysis of morphological criteria and generic neuron marker expression; they did not carefully probe for reexpression of region-specific transcription factors. There is evidence that grafted cells can undergo morphological adaptation in the host region without undergoing respecification such as NSCs grafted into the retina (Takahashi et al. 1998). Future studies will need to revisit these questions using genetic lineage-marking strategies before and after transplantation.

Temporal fate restrictions have been investigated in heterochronic transplantation assays. Such studies have shown that early-stage NSCs have the ability to populate orthotopic regions in older-stage hosts but not vice versa (Frantz and McConnell 1996). Other examples of temporal restrictions are the increased bias of late NSC and neural precursor populations to undergo gliogenic differentiation (Quinn et al. 1999) and, conversely, the unresponsiveness of earlystage cortical NSCs to undergo glial differentiation in response to instructive gliogenic cues based on activating JAK-STAT signaling (Molne et al. 2000). The latter phenomenon has been linked to methylation of critical components of JAK-STAT signaling in early-stage NSCs (Fan et al. 2005). One interpretation of these data is that at any given stage of development, no single NSC possesses the capacity for recreating the full cellular diversity of the CNS (Mukouyama et al. 2006) and that NSCs progress through sequential stages of fate potential from the time of neural induction to adulthood.

A practical example for the difficulties of using NSCs to derive a specialized neuron type is the generation of midbrain dopamine neurons for application in models of Parkinson's disease. Functional midbrain dopamine neurons can be derived from short-term expanded precursors isolated from the early rodent or human midbrain (Studer et al. 1998; Sánchez-Pernaute et al. 2001; Parish et al. 2008). However, more extensive in vitro expansion results in a dramatic decrease in the efficiency to generate dopamine neurons (Yan et al. 2001). Many strategies have been developed in an effort to overcome this limitation, including treatments with extrinsic factors and genetic modification of key developmental genes (for review, see Kriks and Studer 2009). However, the goal of obtaining long-term expandable populations of NSCs yielding authentic midbrain dopamine neurons has remained elusive.

\section{EMBRYONIC STEM CELLS AND THE DERIVATION OF NEURAL FATES}

The challenges for obtaining patternable NSC populations have been addressed using two main strategies: the development of improved protocols for expansion and differentiation of NSC-like populations with defined regional and temporal identity and the search for a novel NSC source with intact neural-plate-stage patterning potential. Mouse ESCs and the more recent isolation of human ESCs (Thomson et al. 1998) offer a powerful paradigm for generating unlimited numbers of early-stage neural progeny. Many protocols have been developed for inducing neural differentiation in ESCs. These include embryoid body (EB) differentiation in combination with retinoic acid treatment, conditioned medium, or neural survival factors (Bain et al. 1995; Okabe et al. 1996; Lee et al. 2000; Zhang et al. 2001; Rathjen et al. 2002); the use of neuron-inducing stromal feeders (Kawasaki et al. 2000, 2002; Barberi et al. 2003; Perrier et al. 2004); and the development of adherent feeder-free approaches (Reubinoff et al. 2001; Cibelli et al. 2002; Ying et al. 2003).

All three basic strategies yield neural progeny at stages suitable for neural patterning studies. Comparative analysis of developmental progression in vitro and in vivo showed a remarkable correlation from the stage of gastrulation to neurulation, patterning, neurogenesis, and gliogenesis (Barberi et al. 2003). Clonogenic experiments have demonstrated that ESC-derived neural progeny can self-renew extensively and clonally give rise to neurons, astrocytes, and oligodendrocytes (Barberi et al. 2003). These results in mouse ESCs provided access to early stages of neural development and yielded ESC-derived multipotent NSC populations in vitro. NSC-like populations have been also obtained from hESCs and demonstrated to engraft in the adult rodent SVZ in vivo and contribute human cells to the host rostral migratory stream and olfactory bulb (Tabar et al. 2005). However, the isolation of ESC-derived NSCs illustrated again the importance of developmental stage and neuronal fate potential. ESCderived neural progeny readily respond to appropriate developmental cues that direct fate toward midbrain dopamine neurons (Lee et al. 2000; Barberi et al. 2003; Perrier et al. 2004), somatic motoneurons (Wichterle et al. 2002; Yan et al. 2005; Lee et al. 2007b), or forebrain neuron types (Barberi et al. 2003; Watanabe et al. 2005, 2007). However, patterning potential is restricted to narrow developmental windows and is lost progressively after in vitro expansion and isolation of FGF-2/EGF-expanded NSC populations (Tabar et al. 2005; Elkabetz et al. 2008). The broad differentiation potential of ESC-derived earlystage neural progeny raises the question of whether these cells reflect a novel, distinct NSC state that can be isolated in vitro and propagated long term under appropriate conditions.

\section{NEURAL ROSETTES}

\section{Original Description of Neural Rosettes}

A striking feature during neural differentiation of hESCs is the formation of neural rosettes. Neural rosettes are an early intermediate composed of radially organized columnar epithelial cells resembling the stage of neurulation. Neural rosette formation has been previously described under pathological conditions such as during tumor formation in teratomas or primitive neuroepithelial tumors (PNETs). Initial studies in hESCs suggested that neural rosettes represent abortive neural tube structures 
(Zhang et al. 2001) expressing a broad range of neural precursor markers including Nestin, NCAM, Pax6, and Sox1. One critical feature of neural rosettes is the close temporal link between rosette formation and neural patterning potential (Perrier et al. 2004; Yan et al. 2005). Neural rosettes also exhibit a high proliferative capacity and a broad differentiation potential along both neuronal and glial lineages (Reubinoff et al. 2001; Zhang et al. 2001). There has been some controversy whether neural patterning is restricted to the earliest stages of neural rosette formation or whether patterning potential is maintained in later-stage rosettes. It has been suggested that expression of Sox1 marks later-stage rosettes with reduced patterning potential (Yan et al. 2005). However, other studies did not observe an obvious delay in the onset of Pax6 versus Sox1 expression and reported intact patterning potential toward midbrain dopamine neuron (Perrier et al. 2004) and spinal motoneuron fates (Lee et al. 2007b) in later-stage rosettes.

Recent work from our lab has characterized the patterning potential of neural rosette-stage cells in more detail and confirmed extensive AP and DV respecification in rosettes (Elkabetz et al. 2008), including the potential to yield neural crest stem cells (NCSCs) and precursor populations (Lazzari et al. 2006; Lee et al. 2007a). Interestingly, neural rosettes do not express distinct markers that define specific DV domains during neural tube formation, as best characterized for the developing spinal cord in vivo (Jessell 2000). The lack of defined DV domains within rosettes suggests that neural rosettes correspond to the neuralplate/neural-fold stage before DV specification, rather than representing abortive neural tube structures.

\section{Stem Cell Nature, Cytoarchitecture, and Progression in Neural Rosettes}

The broad differentiation potential and proliferative capacity of neural rosettes suggest that they may contain patternable NSC-like populations. The demonstration of a self-renewing rosette-stage NSC with intact differentiation potential has been challenging. Propagation of rosettestage cells in FGF-2 and EGF, the growth factors most commonly used in NSC culture, results in the rapid loss of radial organization and the concomitant loss of patterning potential. These findings suggest that the extrinsic milieu (e.g., FGF-2/EGF exposure) suppresses rosette potential, or that proliferation in the presence of FGF-2 and EGF causes progression toward a later nonpatternable state.

The classic definition of NSCs is based on self-renewal potential and trilineage differentiation. In the case of rosette-stage stem cells, this definition may need to be adjusted to include maintenance of rosette cytoarchitecture and - most importantly_patterning potential. Therefore, NCSs at the rosette stage are expected to exhibit selfrenewal and differentiation capacities broader than those observed in classic NSCs.

Neural rosettes and early-stage neuroepithelial cells in vivo share many morphological and functional characteristics including a pronounced apical-basal polarity. The apical side of neuroepithelial cells in vivo faces the amniotic fluid at the neural-plate stage and the neural tube lumen fol- lowing neural tube closure. The basal side is linked to the basal lamina. Neural rosettes maintained in vitro lack equivalents of basal lamina or amniotic cavity. Therefore, apial-basal polarity must be defined based on marker expression and functional characteristics. Throughout the cell cycle, neuroepithelial cells are anchored to one another apically through junctional complexes (Hinds and Ruffett 1971; Aaku-Saraste et al. 1996) characterized by ZO1 expression. Toward mitosis, neuroepithelial cells round up at the apical side, concomitant with interkinetic migration of their nuclei along the apical-basal axis. In vitro, the expression of ZO1 and the location of mitotic nuclei marked by phosphohistone 3 (PH3) define the rosette lumen as the apical side of the rosette structure (Lazzari et al. 2006; Elkabetz et al. 2008). Early-stage neuroepithelial cells, similar to early rosettes in vitro, form a pseudostratified epithelium with all cells touching the lumen (Sauer 1935). As neural rosettes continue to grow in vitro, they mimic the processes occurring during neurulation and neural tube growth. Rosette cells gradually give rise to differentiated cells such as neurons migrating radially away from the rosette structure and a set of more restricted progenitors. The more complex organization of late-stage rosettes is reflected in their multilayered structure. Future studies must address whether the rosette lumen at these late stages continues to exert a niche function and retain a population with intact patterning and proliferation potential or whether all cells in late rosettes undergo progressive fate restrictions.

Early neural rosettes represent a symmetrically dividing undifferentiated neuroepithelial cell population with very small numbers of spontaneously differentiating neurons. This early expansion phase is followed by a neurogenic stage where rosette cells start to efficiently produce neurons. Concomitant to onset of neurogenesis, rosettes give rise to radial glial-like cells expressing classic markers such as brain lipid-binding protein (BLBP) and GLAST. These radial glial-like populations retain features of neuroepithelial cells such as interkinetic nuclear migration and apical endfeet. At later stages, there is a loss of epithelial polarity and increased EGF responsiveness associated with a loss of neurogenic bias and increased production of glial fates.

\section{Forse-1: Anterior Bias and Neural Patterning in Rosettes}

The broad differentiation potential of hESC-derived neural rosettes raises the question of whether cells with true NSC potential can be isolated at that stage. Such rosette-stage NSCs are predicted to combine self-renewal and multilineage differentiation potential with the ability to respond to patterning cues. Forse 1 was previously characterized as a surface marker distinguishing anterior and posterior CNS precursor fates (Tole et al. 1995). The Forse1 antibody allows the separation of rosette-stage cells enriched for anterior markers such as BF-1 (FoxG1B). Forse1-negative rosette cells are enriched for precursors expressing posterior CNS and neural crest markers (Fig. 1). In addition, Forse $1^{-}$cells also include populations of more differentiated neurons and glia as well as nonneural progeny. 


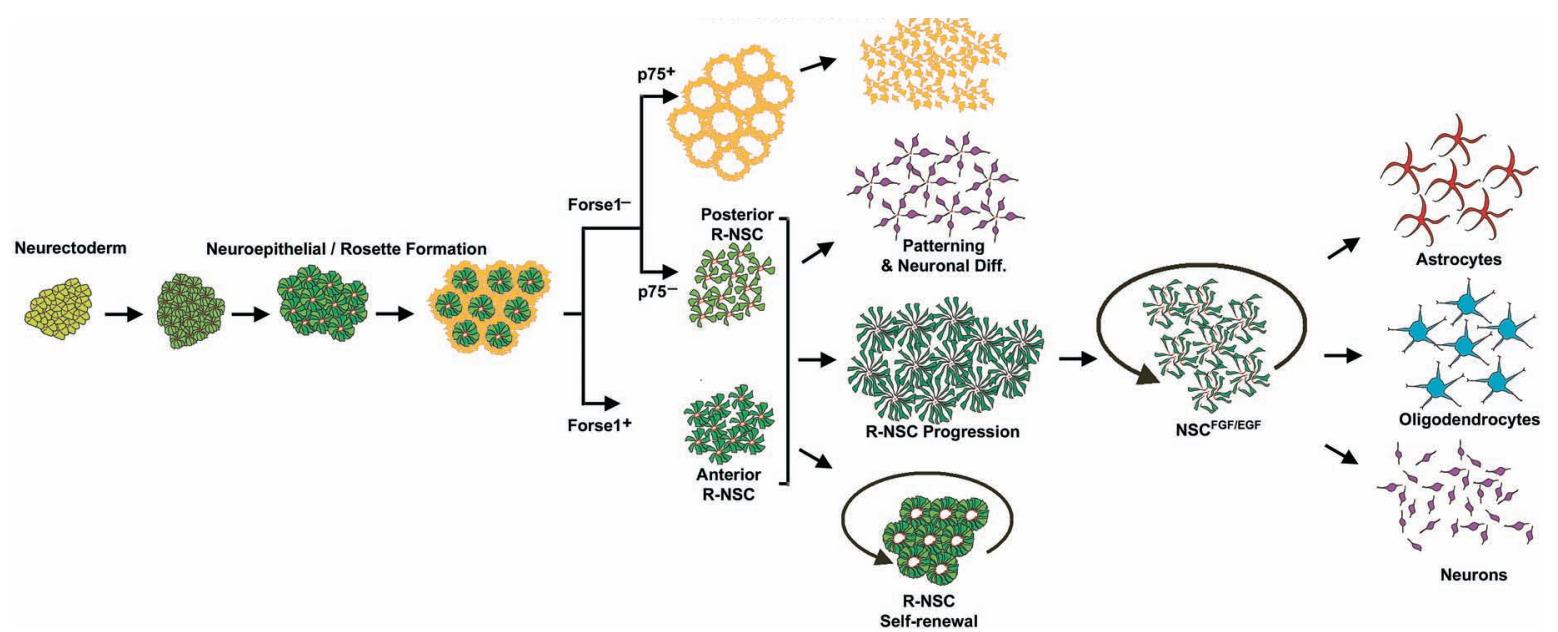

Figure 1. NSC progression model. During neural induction, hESCs form early neuroepithelial structures developing into neural rosette structures. At the rosette stage, cultures can be separated based on Forse1 expression into cells with anterior CNS character and into cells with more posterior markers including neural crest markers. Both anterior and posterior R-NSC-stage cells can be patterned toward a broad range of fates along the AP and DV axes. Depending on culture conditions, R-NSCs can be propagated and give rise to $\mathrm{NSC}^{\mathrm{FGF} / \mathrm{EGF}}$ or yield self-renewing populations of R-NSCs. NSCs ${ }^{\mathrm{FGF} / \mathrm{EGF}}$ also exhibit self-renewal potential and multilineage differentiation toward astrocytes, oligodendrocytes, and neurons but lose patterning potential.

Forse $1^{+}$cells express classic NSC markers including nestin, BLBP, and vimentin while retaining expression of neuroepithelial markers such as Pax6, Sox1, and N-cadherin. Importantly, at the rosette stage, both Forse $1^{+}$and Forse $1^{-}$cells contain population of cells that can be respecified in response to appropriate AP and DV patterning cues (Elkabetz et al. 2008). Clonal studies have revealed that single Forse $1^{+}$cells are capable of selfrenewal, multilineage differentiation, and neural pattern- ing, the key features that define NSCs at the rosette stage. These data indicate that rosettes contain regionally biased NSC populations that can be prospectively identified and that retain broad differentiation potential at the clonal level, termed R-NSCs. Figure 2 presents a summary of markers that distinguish R-NSCs from both undifferenti-

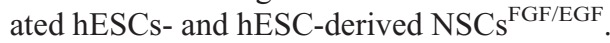

Identification of an R-NSC-specific molecular profile was based on the hypothesis that independent of their

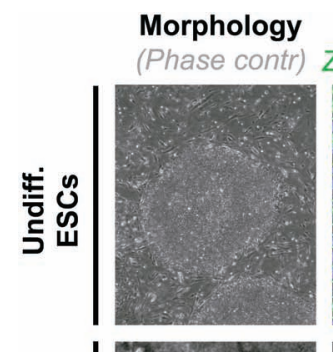

Polarity

NSC Markers

R-NSC Markers

Patterning
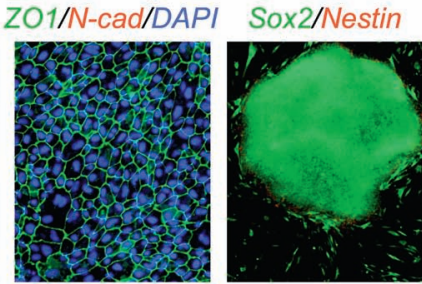

PLZF/ZO1/DAPI

Tuj1/HB9
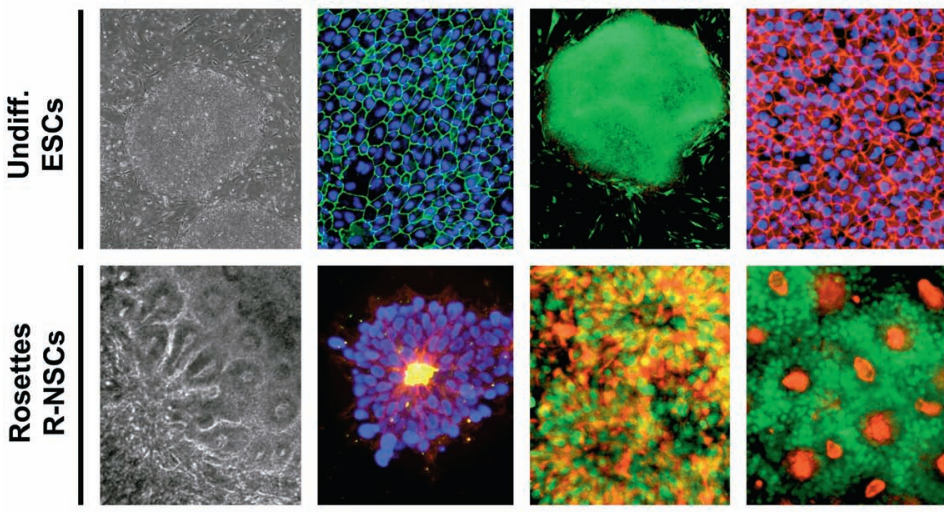

N/A
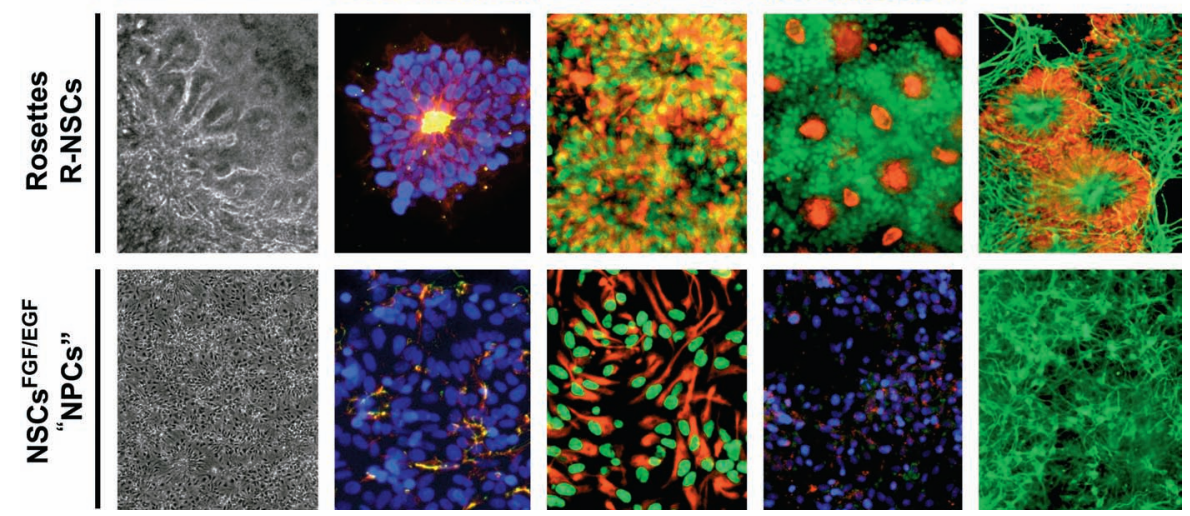

Figure 2. Marker and functional panel distinguishing ESCs, R-NSCs, and NSCs ${ }^{\text {FGF/EGF }}$. Representative markers show rosette cytoarchitecture ("morphology"), cell polarity, NSC identity, R-NSC state, and the ability of the cells to differentiate in region-specific neurons such as somatic motoneurons (patterning). 
regional bias $\left(\right.$ Forse $^{+}$or Forse $1^{-}$), R-NSCs share a molecular profile distinct from undifferentiated hESCs and NSCs ${ }^{\mathrm{FGF}-2 / \mathrm{EGF}}$. R-NSC markers identified by global transcriptome analysis were highly enriched in nuclear proteins including transcription factors and transcriptional regulators (Elkabetz et al. 2008). Most R-NSC genes have not been previously associated with neural development and NSC biology, although most of them are expressed during early neural development in the mouse (www.informatics.jax.org). Null mutations for many of the R-NSC-specific markers do not result in major CNS defects, suggesting functional redundancy. However, these studies did not directly study CNS impact of these genes and may have missed more subtle neural phenotypes. On the basis of our studies, we predict - given the narrow developmental windows of expression-that more dramatic effects may be observed in gain-of-function rather than in loss-of-function studies. Gene ontology analysis revealed that gene expression in R-NSCs is enriched for components of the Notch, $\mathrm{SHH}$, and Wnt signaling pathways and is distinct from NSC ${ }^{\text {FGF/EGF. }}$

\section{Growth Requirements and Intrinsic Growth Potential}

A strong temporal correlation exists between patterning potential and rosette cytoarchitecture, although there is no evidence that rosette organization is directly required for mediating patterning response. When R-NSCs are first derived from hESCs, they rapidly expand in number and spontaneously form secondary rosettes, suggesting that a default intrinsic program drives R-NSC self-renewal. However, as R-NSCs progress in culture, this program is down-regulated as reflected by reduced proliferation potential, and the loss of rosette cytoarchitecture and patterning potential and becomes dependent on extrinsic factors. Therefore, a key question in R-NSC biology is the identification of extrinsic factors that promote R-NSC selfrenewal.

Two well-known factors for propagating NSCs are FGF-2 and EGF. Both factors have been shown to promote in vitro proliferation of NSCs and neural precursors from many regions of the developing and adult CNS (Murphy et al. 1990; Reynolds and Weiss 1992; Kilpatrick and Bartlett 1993; Ray et al. 1993; Gritti et al. 1995; Johe et al. 1996; Kalyani et al. 1997; Studer et al. 1998). FGF-2dependent proliferation in vitro is compatible with the early expression of FGF-R1 (FGF-receptor-1) and FGF-2 in the CNS (Orr-Urtreger et al. 1991; Wanaka et al. 1991), defects in cell proliferation associated with targeted deletion of these receptors (Yamaguchi et al. 1994; Ciruna et al. 1997; Raballo et al. 2000), and the proliferative effects following FGF-2 administration in vivo (Kuhn et al. 1997). EGF exposure also has well-known effects in the developing and adult SVZ (Craig et al. 1996; Doetsch et al. 2002) and is required for normal forebrain development at late embryonic and postnatal stages (Sibilia and Wagner 1995; Threadgill et al. 1995). Despite the important role of FGF-2 and EGF for NSCs in vitro and in vivo, at the rosette stage, FGF-2 and EGF treatments cause a rapid loss of rosette cytoarchitecture and patterning potential (Shin et al. 2006; Elkabetz et al. 2008). Another problem regarding FGF-2 treatment at the R-NSC stage is the induction of non-CNS cells with neural crest and mesenchymal precursor features (Lee et al. 2007a; Elkabetz et al. 2008).

There are multiple lines of evidence for the importance of Notch signaling at the R-NSC stage. First, components of Notch signaling were selectively enriched in R-NSCs (Elkabetz et al. 2008). Second, high cell density promotes growth of R-NSCs and maintenance of rosette cytoarchitecture, and both of these responses can be blocked by Notch inhibition via the $\gamma$-secretase inhibitor DAPT $(N$ [N-(3,5-difluorophenacetyl)-L-alanyl]-S-phenylglycine $t$ butylester). Third, addition of recombinant proteins activating notch signaling including D114 and Jagged-1 promotes R-NSC maintenance (Elkabetz et al. 2008). However, Notch downstream effectors such as Hes1 and

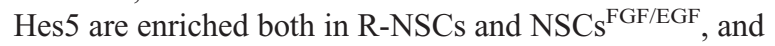
a role for Notch signaling is not restricted to the R-NSC state given its well-known effects in many NSC paradigms (Gaiano et al. 2000; Ohtsuka et al. 2001; AndroutsellisTheotokis et al. 2006; Mizutani et al. 2007). Therefore, it remains to be determined whether certain aspects of Notch signaling selectively impact the R-NSC state or whether Notch exerts a more generic self-renewal effect in RNSCs, similar to its role in other NSC populations.

SHH has many fundamental roles in early neural development as both a morphogen and a proliferation factor. Ablation of SHH during mouse development causes many abnormalities in CNS patterning and beyond (Chiang et al. 1996). Conditional ablation studies in the CNS have revealed a role for $\mathrm{SHH}$ signaling in the maintenance of neural stem and precursor cells during development and adulthood (Ishibashi and McMahon 2002; Lai et al. 2003; Machold et al. 2003; Ahn and Joyner 2005; Palma et al. 2005). We observed that SHH is a potent mitogen for RNSCs, inducing rapid proliferation over multiple passages without impacting rosette cytoarchitecture or gene expression profiles (see Fig. 3) (Elkabetz et al. 2008). However, it remains to be determined whether $\mathrm{SHH}$ acts by selectively promoting R-NSC proliferation, promoting R-NSC identity via inducing R-NSC-specific genes, repressing progression to $\mathrm{NSC}^{\mathrm{FGF} / \mathrm{EGF}}$ state, or, in part, preventing differentiation toward dorsal fates including neural crest precursors.

\section{Molecular Dissection of R-NSC Development}

A striking illustration of the R-NSC state is the unique molecular signature as defined by global gene expression analysis comparing undifferentiated hESCs to R-NSC and NSC ${ }^{\text {FGF/EGF }}$ progeny (Fig. 4). The identification of large sets of R-NSC-specific genes opens up new opportunities for defining the R-NSC state and the associated neural patterning potential at the functional levels. However, temporal analysis of gene expression also provides a better understanding for the molecular events involved in R-NSC induction and progression to the $\mathrm{NSC}^{\mathrm{FGF} / \mathrm{EGF}}$ state.

At the level of cell adhesion, an early switch from Ecadherin expression in undifferentiated hESCs to N-cad-

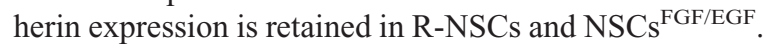



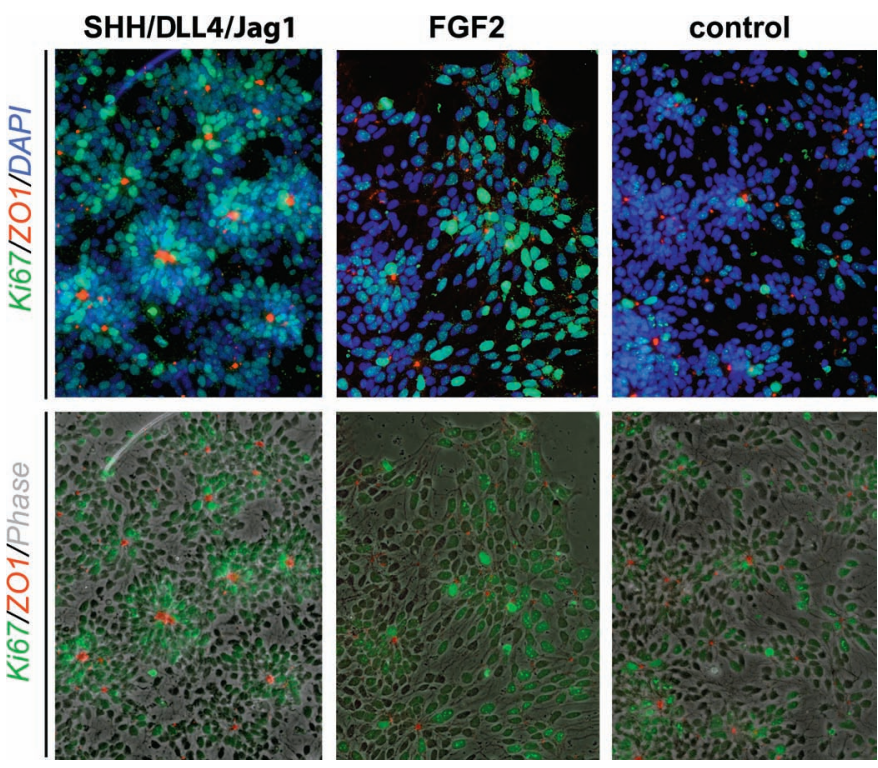

Figure 3. R-NSC maintenance and proliferation. Labeling of cells using Ki67 reveals that SHH/DLL4/ Jag1 and FGF-2 treatments induce proliferation compared with untreated control cultures. However, only SHH/DLL4/Jag1 treatment efficiently maintains RNSC cytoarchitecture, whereas FGF-2 treatment causes a progressive loss of cell polarity.

R-NSCs and NSCs ${ }^{\mathrm{FGF} / \mathrm{EGF}}$ also share expression of classic neuroepithelial and radial glial markers such as Sox1, Sox2, Hes5, and Pax6. The increasing radial glial nature of R-NSCs and $\mathrm{NSCs}^{\mathrm{FGF} / \mathrm{EGF}}$ is further illustrated by the temporal expression of FABP7 and SLC1A3 (GLAST) (Fig. 4). One striking feature of R-NSCs is their pronounced polarity, and several key polarity genes includ- ing CDC42 and Par6 show peak expression in R-NSCs. The greatest temporal specificity is observed for bona fide R-NSC markers (Elkabetz et al. 2008) such as Plagl1, Dach1, and Zbtb16 (PLZF).

The patterning potential of R-NSCs likely reflects an epigenetic state permissive for plasticity. Recent studies have demonstrated reprogramming of somatic cells back
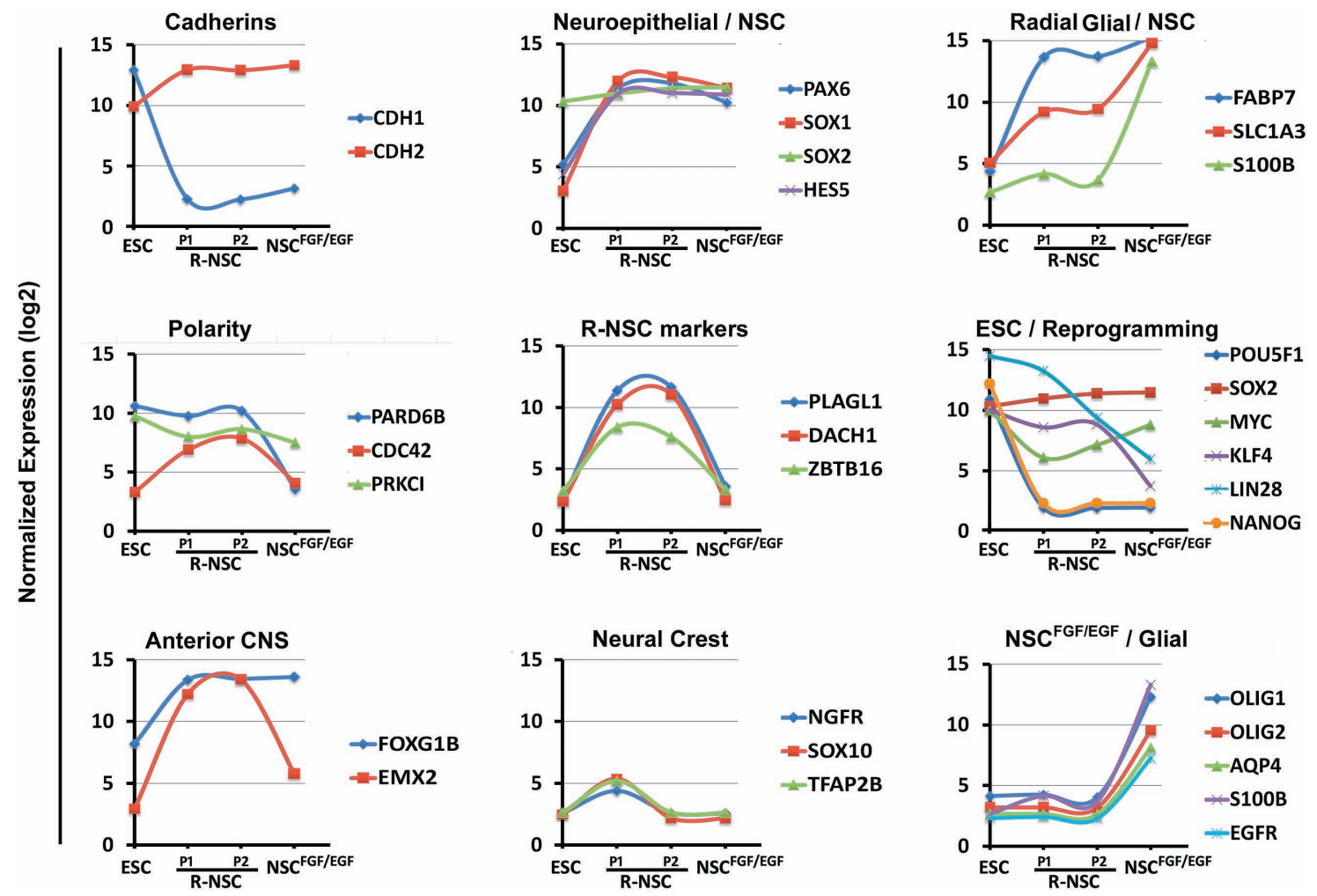

Figure 4. Expression of molecular markers: Time course analysis. Selected markers are shown grouped into specific functional categories (for details, see text). 
to a pluripotent state using defined sets of transcription factors or RNA-binding proteins (Takahashi and Yamanaka 2006; Takahashi et al. 2007; Yu et al. 2007). We observed that expression of these reprogramming factors is rapidly abolished in the case of Oct4 (POU5F1) and Nanog. However, R-NSCs selectively retain high levels of LIN28, and levels of Sox 2 and Klf4 were similar to

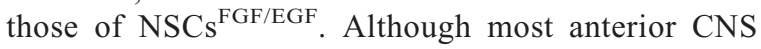
markers such as FoxG1 are expressed highly in both R-

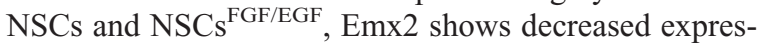
sion at the $\mathrm{NSCs}^{\mathrm{FGF} / \mathrm{EGF}}$ state. However, other anterior markers including D1x1 and Dlx2 show increased expression in $\mathrm{NSC}^{\mathrm{FGF} / \mathrm{EGF}}$ (data not shown). Finally, our data indicate that neural crest potential (P1 R-NSCs) and glial differentiation bias (NSCs ${ }^{\mathrm{FGF} / \mathrm{EGF}}$ ) can be predicted based on global gene expression profiles.

In summary, molecular analysis offers insights into the sequential events controlling NSC progression. These studies also identified many potential markers for the prospective isolation of R-NSCs and NSCs ${ }^{\text {FGF/EGF }}$ using genetic reporter lines. Importantly, molecular analysis also provides a high priority list of targets for functional interventions aimed at enhancing R-NSC self-renewal and preventing or reversing progression to the $\mathrm{NSCs}^{\mathrm{FGF} / \mathrm{EGF}}$ state.

\section{CONCLUSIONS AND QUESTIONS FOR THE FUTURE}

The isolation of hESC-derived R-NSCs raises many key questions for future exploration. One obvious task is defining the role of R-NSC-specific genes in self-renewal and patterning potential and testing whether ectopic expression of key R-NSC genes in NSC ${ }^{\mathrm{FGF} / \mathrm{EGF}}$ is sufficient to reverse the R-NSC state. R-NSC markers are also critical for defining cell heterogeneity and lineage relationships within R-NSCs. Another issue relevant for future translation is the development of improved protocols harnessing the patterning potential of R-NSCs while reducing the risk for neural overgrowth, as commonly observed in hESCderived neural progeny-grafting paradigms (SánchezPernaute et al. 2005; Ferrari et al. 2006; Roy et al. 2006; Aubry et al. 2008; Elkabetz et al. 2008).

Beyond the role of R-NSCs in hESC biology, it will be important to identify potential endogenous R-NSC populations. Initial studies suggest that R-NSC-like populations can be isolated from mouse embryos at the neural-plate stage (E8.25) (Elkabetz et al. 2008). The availability of genetic markers should allow prospective isolation of R-NSCs from primary tissue and in vivo lineage marking. Although current data suggest that R-NSCs represent a highly transient cell population, it will be critical to confirm whether R-NSC-like cells can persist into postnatal and adult stages.

The striking cytoarchitecture of rosettes raises the question of whether cell organization and cell-to-cell contact is critical for aspects of R-NSC biology such as self-renewal and symmetric division capacity or patterning potential. To this end, tools need to be developed that selectively disrupt polarity at the R-NSC stage. Given the emergence of rosette structures in many neural tumor types such as PNETs or medulloblastomas, understanding these struc- ture/function relationships may provide insights beyond the neural stem cell field.

One fundamental idea of rosette biology is that similar to ESCs at the inner cell mass (ICM) stage, R-NSCs may capture a defined developmental state such as the neuralplate stage and perpetuate early cell potential in vitro. Such an "ES cell equivalent of the nervous system" could become a powerful tool for translational medicine and for applications in high-throughput screening assays requiring large numbers of homogeneous cell populations. Such a paradigm may for the first time provide access to a universal NSC stage capable of recreating the complete cellular diversity of the central and peripheral nervous systems.

\section{ACKNOWLEDGMENTS}

We thank members of the Studer lab for valuable discussions of the manuscript and Sonja Clairmont and Yael Strulovici for continued technical support. Our own work described in this review was supported by the National Institutes of Health (grants 1R01NS052671, 5R01NS044819), NYSTEM, the Starr Foundation, and Project ALS.

\section{REFERENCES}

Aaku-Saraste, E., Hellwig, A., and Huttner, W.B. 1996. Loss of occludin and functional tight junctions, but not ZO-1, during neural tube closure-Remodeling of the neuroepithelium prior to neurogenesis. Dev. Biol. 180: 664-679.

Ahn, S. and Joyner, A.L. 2005. In vivo analysis of quiescent adult neural stem cells responding to Sonic hedgehog. Nature 437: 894-897.

Altman, J. and Das, G.D. 1965. Autoradiographic and histological evidence of postnatal hippocampal neurogenesis in rats. $J$. Comp. Neurol. 124: 319-335.

Alvarez-Buylla, A. and Lim, D.A. 2004. For the long run: Maintaining germinal niches in the adult brain. Neuron 41: 683-686.

Androutsellis-Theotokis, A., Leker, R.R., Soldner, F., Hoeppner, D.J., Ravin, R., Poser, S.W., Rueger, M.A., Bae, S.K., Kittappa, R., and McKay, R.D. 2006. Notch signalling regulates stem cell numbers in vitro and in vivo. Nature 442: 823-826.

Aubry, L., Bugi, A., Lefort, N., Rousseau, F., Peschanski, M., and Perrier, A.L. 2008. Striatal progenitors derived from human ES cells mature into DARPP32 neurons in vitro and in quinolinic acid-lesioned rats. Proc. Natl. Acad. Sci. 105: 16707-16712.

Bain, G., Kitchens, D., Yao, M., Huettner, J.E., and Gottlieb, D.I. 1995. Embryonic stem cells express neuronal properties in vitro. Dev. Biol. 168: 342-357.

Barberi, T., Klivenyi, P., Calingasan, N.Y., Lee, H., Kawamata, H., Loonam, K., Perrier, A.L., Bruses, J., Rubio, M.E., Topf, N., et al. 2003. Neural subtype specification of fertilization and nuclear transfer embryonic stem cells and application in parkinsonian mice. Nat. Biotechnol. 21: 1200-1207.

Bertrand, N., Medevielle, F., and Pituello, F. 2000. FGF signalling controls the timing of Pax6 activation in the neural tube. Development 127: 4837-4843.

Brüstle, O., Maskos, U., and McKay, R.D.G. 1995. Host-guided migration allows targeted introduction of neurons into the embryonic brain. Neuron 15: 1275-1285.

Caldwell, M.A., He, X.L., Wilkie, N., Pollack, S., Marshall, G., Wafford, K.A., and Svendsen, C.N. 2001. Growth factors regulate the survival and fate of cells derived from human neurospheres. Nat. Biotechnol. 19: 475-479.

Campbell, K., Olsson, M., and Björklund, A. 1995. Regional incorporation and site-specific differentiation of striatal precursors transplanted to the embryonic forebrain ventricle. Neuron 15: $1259-1273$. 
Capela, A. and Temple, S. 2002. LeX/ssea-1 is expressed by adult mouse CNS stem cells, identifying them as nonependymal. Neuron 35: 865-875.

Cattaneo, E. and McKay, R. 1990. Proliferation and differentiation of neuronal stem cells regulated by nerve growth factor. Nature 347: 762-765.

Chang, C.B. and Hemmati-Brivanlou, A. 1998. Cell fate determination in embryonic ectoderm. J. Neurobiol. 36: 128-151.

Chiang, C., Litingtung, Y., Lee, E., Young, K.E., Corden, J.L., Westphal, H., and Beachy, P.A. 1996. Cyclopia and defective axial patterning in mice lacking Sonic hedgehog gene function. Nature 383: 407-413.

Chmielnicki, E., Benraiss, A., Economides, A.N., and Goldman, S.A. 2004. Adenovirally expressed noggin and brain-derived neurotrophic factor cooperate to induce new medium spiny neurons from resident progenitor cells in the adult striatal ventricular zone. J. Neurosci. 24: 2133-2142.

Cibelli, J.B., Grant, K.A., Chapman, K.B., Cunniff, K., Worst, T., Green, H.L., Walker, S.J., Gutin, P.H., Vilner, L., Tabar, V., et al. 2002. Parthenogenetic stem cells in nonhuman primates. Science 295: 819.

Ciruna, B.G., Schwartz, L., Harpal, K., Yamaguchi, T.P., and Rossant, J. 1997. Chimeric analysis of fibroblast growth factor receptor-1 (Fgfrl) function: A role for FGFR1 in morphogenetic movement through the primitive streak. Development 124: 2829-2841.

Conti, L., Pollard, S.M., Gorba, T., Reitano, E., Toselli, M., Biella, G., Sun, Y.R., Sanzone, S., Ying, Q.L., Cattaneo, E., and Smith, A. 2005. Niche-independent symmetrical self-renewal of a mammalian tissue stem cell. PLoS Biol. 3: e283

Craig, C.G., Tropepe, V., Morshead, C.M., Reynolds, B.A., Weiss, S., and van der Kooy, D. 1996. In vivo growth factor expansion of endogenous subependymal neural precursor cell populations in the adult mouse brain. J. Neurosci. 16: 2649-2658.

Crossley, P.H., Minowada, G., MacArthur, C.A., and Martin, G.R. 1996. Roles for FGF8 in the induction, initiation, and maintenance of chick limb development. Cell 84: 127-136.

Davis, A.A. and Temple, S. 1994. A self-renewing multipotential stem cell in embryonic rat cerebral cortex. Nature 372: 263 266.

Doetsch, F., Caille, I., Lim, D.A., Garcia-Verdugo, J.M., and Alvarez-Buylla, A. 1999. Subventricular zone astrocytes are neural stem cells in the adult mammalian brain. Cell 97: 703-716.

Doetsch, F., Petreanu, L., Caille, I., Garcia-Verdugo, J.M., and Alvarez-Buylla, A. 2002. EGF converts transit-amplifying neurogenic precursors in the adult brain into multipotent stem cells. Neuron 36: 1021-1034.

Elkabetz, Y., Panagiotakos, G., Al Shamy, G., Socci, N.D., Tabar, V., and Studer, L. 2008. Human ES cell-derived neural rosettes reveal a functionally distinct early neural stem cell stage. Genes Dev. 22: 152-165.

Fan, G., Martinowich, K., Chin, M.H., He, F., Fouse, S.D., Hutnick, L., Hattori, D., Ge, W., Shen, Y., Wu, H., et al. 2005. DNA methylation controls the timing of astrogliogenesis through regulation of JAK-STAT signaling. Development 132: 3345-3356.

Ferrari, D., Sánchez-Pernaute, R., Lee, H., Studer, L., and Isacson, O. 2006. Transplanted dopamine neurons derived from primate ES cells preferentially innervate DARPP-32 striatal progenitors within the graft. Eur. J. Neurosci. 24: 1885-1896.

Fishell, G. 1995. Striatal precursors adopt cortical identities in response to local cues. Development 121: 803-812.

Frantz, G.D. and McConnell, S.K. 1996. Restriction of late cerebral cortical progenitors to an upper-layer fate. Neuron 17: 55-61.

Frederiksen, K. and McKay, R.D. 1988. Proliferation and differentiation of rat neuroepithelial precursor cells in vivo. $J$. Neurosci. 8: 1144-1151.

Gabay, L., Lowell, S., Rubin, L., and Anderson, D.J. 2003. Deregulation of dorsoventral patterning by FGF confers trilineage differentiation capacity on CNS stem cells in vitro. Neuron 40: 485-499.

Gage, F.H. 2000. Mammalian neural stem cells. Science 287:
$1433-1438$.

Gaiano, N., Nye, J.S., and Fishell, G. 2000. Radial glial identity is promoted by Notch1 signaling in the murine forebrain. Neuron 26: 395-404.

Galli, R., Pagano, S.F., Gritti, A., and Vescovi, A.L. 2000. Regulation of neuronal differentiation in human CNS stem cell progeny by leukemia inhibitory factor. Dev. Neurosci. 22: 8695.

Goldman, S.A. and Nottebohm, F. 1983. Neuronal production, migration, and differentiation in a vocal control nucleus of the adult female canary brain. Proc. Natl. Acad. Sci. 80: 2390-2394.

Gritti, A., Cova, L., Parati, E.A., Galli, R., and Vescovi, A.L. 1995. Basic fibroblast growth factor supports the proliferation of epidermal growth factor-generated neuronal precursor cells of the adult mouse CNS. Neurosci. Lett. 185: 151-154.

$\mathrm{He}$, W., Ingraham, C., Rising, L., Goderie, S., and Temple, S. 2001. Multipotent stem cells from the mouse basal forebrain contribute GABAergic neurons and oligodendrocytes to the cerebral cortex during embryogenesis. J. Neurosci. 21: 8854 8862.

Hinds, J.W. and Ruffett, T.L. 1971. Cell proliferation in the neural tube: An electron microscopic and Golgi analysis in the mouse cerebral vesicle. Z. Zellforsch. Mikrosk. Anat. 115: 226 264.

Hynes, M., Poulsen, K., Tessier-Lavigne, M., and Rosenthal, A. 1995. Control of neuronal diversity by the floor plate: Contactmediated induction of midbrain dopaminergic neurons. Cell 80: $95-101$.

Ishibashi, M. and McMahon, A.P. 2002. A sonic hedgehogdependent signaling relay regulates growth of diencephalic and mesencephalic primordia in the early mouse embryo. Development 129: 4807-4819.

Jain, M., Armstrong, R.J., Tyers, P., Barker, R.A., and Rosser, A.E. 2003. GABAergic immunoreactivity is predominant in neurons derived from expanded human neural precursor cells in vitro. Exp. Neurol. 182: 113-123.

Jessell, T.M. 2000. Neuronal specification in the spinal cord: Inductive signals and transcriptional codes. Nat. Rev. Genet. 1: 20-29.

Johe, K.K., Hazel, T.G., Müller, T., Dugich-Djordjevic, M.M., and McKay, R.D.G. 1996. Single factors direct the differentiation of stem cells from the fetal and adult central nervous system. Genes Dev. 10: 3129-3140.

Kalyani, A., Hobson, K., and Rao, M.S. 1997. Neuroepithelial stem cells from the embryonic spinal cord: Isolation, characterization, and clonal analysis. Dev. Biol. 186: 202-223.

Kawasaki, H., Mizuseki, K., Nishikawa, S., Kaneko, S., Kuwana, Y., Nakanishi, S., Nishikawa, S., and Sasai, Y. 2000. Induction of midbrain dopaminergic neurons from ES cells by stromal cell-derived inducing activity. Neuron 28: 31-40.

Kawasaki, H., Suemori, H., Mizuseki, K., Watanabe, K., Urano, F., Ichinose, H., Haruta, M., Takahashi, M., Yoshikawa, K., Nishikawa, S.I., Nakatsuji, N., and Sasai, Y. 2002. Generation of dopaminergic neurons and pigmented epithelia from primate ES cells by stromal cell-derived inducing activity. Proc. Natl. Acad. Sci. 99: 1580-1585.

Kilpatrick, T.J. and Bartlett, P.F. 1993. Cloning and growth of multipotential neural precursors: Requirements for proliferation and differentiation. Neuron 10: 255-265.

Kondo, T. and Raff, M. 2000. Oligodendrocyte precursor cells reprogrammed to become multipotential CNS stem cells. Science 289: 1754-1757.

Kriks, S. and Studer, L. 2009. Protocols for generating ES cellderived dopamine neurons. In Development and engineering of dopamine neurons (ed. R.J. Pasterkamp et al.). Landes Biosciences, Austin, Texas. (In press.)

Kuhn, H.G., Winkler, J., Kempermann, G., Thal, L.J., and Gage, F.H. 1997. Epidermal growth factor and fibroblast growth factor-2 have different effects on neural progenitors in the adult rat brain. J. Neurosci. 17: 5820-5829.

Lai, K., Kaspar, B.K., Gage, F.H., and Schaffer, D.V. 2003. Sonic hedgehog regulates adult neural progenitor proliferation in vitro and in vivo. Nat. Neurosci. 6: 21-27.

Lazzari, G., Colleoni, S., Giannelli, S.G., Brunetti, D., Colombo, 
E., Lagutina, I., Galli, C., and Broccoli, V. 2006. Direct derivation of neural rosettes from cloned bovine blastocysts: A model of early neurulation events and neural crest specification in vitro. Stem Cells 24: 2514-2521.

Lee, G., Kim, H., Elkabetz, Y., Alshamy, G., Panagiotakos, G., Barberi, T., Tabar, V., and Studer, L. 2007a. Isolation and directed differentiation of neural crest stem cells derived from human embryonic stem cells. Nat. Biotechnol. 25: 1468-1475.

Lee, H.J., Al Shamy, G., Elkabetz, Y., Schoefield, C., Harrison, N.L., Panagiotakos, G., Tabar, V., and Studer, L. 2007b. Directed differentiation and transplantation of human embryonic stem cell derived motoneurons. Stem Cells 25: 19311939.

Lee, S.-H., Lumelsky, N., Studer, L., Auerbach, J.M., and McKay, R.D.G. 2000. Efficient generation of midbrain and hindbrain neurons from mouse embryonic stem cells. Nat. Biotechnol. 18: 675-679.

Ling, Z.D., Potter, E.D., Lipton, J.W., and Carvey, P.M. 1998. Differentiation of mesencephalic progenitor cells into dopaminergic neurons by cytokines. Exp. Neurol. 149: 411-423.

Lumsden, A. and Krumlauf, R. 1996. Patterning the vertebrate neuraxis. Science 274: 1109-1115.

Machold, R., Hayashi, S., Rutlin, M., Muzumdar, M.D., Nery, S., Corbin, J.G., Gritli-Linde, A., Dellovade, T., Porter, J.A., Rubin, L.L., et al. 2003. Sonic hedgehog is required for progenitor cell maintenance in telencephalic stem cell niches. Neuron 39: 937-950.

Markakis, E.A., Palmer, T.D., Randolph-Moore, L., Rakic, P., and Gage, F.H. 2004. Novel neuronal phenotypes from neural progenitor cells. J. Neurosci. 24: 2886-2897.

Mayer-Proschel, M., Kalyani, A.J., Mujtaba, T., and Rao, M.S. 1997. Isolation of lineage-restricted neuronal precursors from multipotent neuroepithelial stem cells. Neuron 19: 773-785.

McKay, R.D. 1997. Stem cells in the central nervous system. Science 276: 66-71.

Merkle, F.T., Mirzadeh, Z., and Alvarez-Buylla, A. 2007. Mosaic organization of neural stem cells in the adult brain. Science 317: 381-384.

Mizutani, K., Yoon, K., Dang, L., Tokunaga, A., and Gaiano, N. 2007. Differential Notch signalling distinguishes neural stem cells from intermediate progenitors. Nature 449: 351-355.

Molne, M., Studer, L., Tabar, V., Ting, Y.-T., Eiden, M.V., and McKay, R.D. 2000. Early cortical precursors do not undergo LIF-mediated astrocytic differentiation. J. Neurosci. Res. 59: 301-311.

Morrison, S.J., Uchida, N., and Weissman, I.L. 1995. The biology of hematopoietic stem cells. Annu. Rev. Cell Dev. Biol. 11: 3571.

Mukouyama, Y.S., Deneen, B., Lukaszewicz, A., Novitch, B.G., Wichterle, H., Jessell, T.M., and Anderson, D.J. 2006. Olig2 ${ }^{+}$ neuroepithelial motoneuron progenitors are not multipotent stem cells in vivo. Proc. Natl. Acad. Sci. 103: 1551-1556.

Murphy, M., Drago, J., and Bartlett, P.F. 1990. Fibroblast growth factor stimulates the proliferation and differentiation of neural precursor cells in vitro. J. Neurosci. Res. 25: 463-475.

Ohtsuka, T., Sakamoto, M., Guillemot, F., and Kageyama, R. 2001. Roles of the basic helix-loop-helix genes Hes 1 and Hes 5 in expansion of neural stem cells of the developing brain. $J$. Biol. Chem. 276: 30467-30474.

Okabe, S., Forsberg-Nilsson, K., Spiro, A.C., Segal, M., and McKay, R.D.G. 1996. Development of neuronal precursor cells and functional postmitotic neurons from embryonic stem cells in vitro. Mech. Dev. 59: 89-102.

Orr-Urtreger, A., Givol, D., Yayon, A., Yarden, Y., and Lonai, P. 1991. Developmental expression of two murine fibroblast growth factor receptors, flg and bek. Development 113: 14191434.

Palma, V., Lim, D.A., Dahmane, N., Sánchez, P., Brionne, T.C., Herzberg, C.D., Gitton, Y., Carleton, A., Alvarez-Buylla, A., and Ruiz i Altaba, A. 2005. Sonic hedgehog controls stem cell behavior in the postnatal and adult brain. Development 132: 335-344.

Palmer, T.D., Ray, J., and Gage, F.H. 1995. FGF-2-responsive neuronal progenitors reside in proliferative and quiescent regions of the adult rodent brain. Mol. Cell. Neurosci. 6: $474-$ 486.

Palmer, T.D., Takahashi, J., and Gage, F.H. 1997. The adult rat hippocampus contains primordial neural stem cells. Mol. Cell. Neurosci. 8: 389-404.

Parish, C.L., Castelo-Branco, G., Rawal, N., Tonnesen, J., Sorensen, A.T., Salto, C., Kokaia, M., Lindvall, O., and Arenas, E. 2008. Wnt5a-treated midbrain neural stem cells improve dopamine cell replacement therapy in parkinsonian mice. $J$. Clin. Invest. 118: 149-160.

Perrier, A.L., Tabar, V., Barberi, T., Rubio, M.E., Bruses, J., Topf, N., Harrison, N.L., and Studer, L. 2004. Derivation of midbrain dopamine neurons from human embryonic stem cells. Proc. Natl. Acad. Sci. 101: 12543-12548.

Qian, X.M., Shen, Q., Goderie, S.K., He, W.L., Capela, A., Davis, A.A., and Temple, S. 2000. Timing of CNS cell generation: A programmed sequence of neuron and glial cell production from isolated murine cortical stem cells. Neuron 28: 69-80.

Quinlan, G.A., Williams, E.A., Tan, S.S., and Tam, P.P. 1995. Neuroectodermal fate of epiblast cells in the distal region of the mouse egg cylinder: Implication for body plan organization during early embryogenesis. Development 121: 87-98.

Quinn, S.M., Walters, W.M., Vescovi, A.L., and Whittemore, S.R. 1999. Lineage restriction of neuroepithelial precursor cells from fetal human spinal cord. J. Neurosci. Res. 57: 590602.

Raballo, R., Rhee, J., Lyn-Cook, R., Leckman, J.F., Schwartz, M.L., and Vaccarino, F.M. 2000. Basic fibroblast growth factor (Fgf2) is necessary for cell proliferation and neurogenesis in the developing cerebral cortex. J. Neurosci. 20: 5012-5023.

Rathjen, J., Haines, B.P., Hudson, K.M., Nesci, A., Dunn, S., and Rathjen, P.D. 2002. Directed differentiation of pluripotent cells to neural lineages: Homogeneous formation and differentiation of a neurectoderm population. Development 129: 2649-2661.

Ray, J., Peterson, D.A., Schinstine, M., and Gage, F.H. 1993. Proliferation, differentiation, and long-term culture of primary hippocampal neurons. Proc. Natl. Acad. Sci. 90: 3602-3606.

Reubinoff, B.E., Itsykson, P., Turetsky, T., Pera, M.F., Reinhartz, E., Itzik, A., and Ben Hur, T. 2001. Neural progenitors from human embryonic stem cells. Nat. Biotechnol. 19: 1134-1140.

Reynolds, B.A. and Weiss, S. 1992. Generation of neurons and astrocytes from isolated cells of the adult mammalian central nervous system (comments). Science 255: 1707-1710.

Rietze, R.L., Valcanis, H., Brooker, G.F., Thomas, T., Voss, A.K., and Bartlett, P.F. 2001. Purification of a pluripotent neural stem cell from the adult mouse brain. Nature 412: 736-739.

Roelink, H., Porter, J.A., Chiang, C., Tanabe, Y., Chang, D.T., Beachy, P.A., and Jessell, T.M. 1995. Floor plate and motor neuron induction by different concentrations of the amino-terminal cleavage product of sonic hedgehog autoproteolysis. Cell 81: 445-455.

Roelink, H., Augsburger, A., Heemskerk, J., Korzh, V., Norlin, S., Ruiz i Altaba, A., Tanabe,Y., Placzek, M., Edlund, T., and Jessell, T.M. 1994. Floor plate and motor neuron induction by vhh-1, a vertebrate homolog of hedgehog expressed by the notochord. Cell 76: 761-775.

Roy, N.S., Cleren, C., Singh, S.K., Yang, L., Beal, M.F., and Goldman, S.A. 2006. Functional engraftment of human ES cellderived dopaminergic neurons enriched by coculture with telomerase-immortalized midbrain astrocytes. Nat. Med. 12: $1259-1268$.

Sánchez-Pernaute, R., Studer, L., Bankiewicz, K.S., Major, E.O., and McKay, R.D. 2001. In vitro generation and transplantation of precursor-derived human dopamine neurons. J. Neurosci. Res. 65: 284-288.

Sánchez-Pernaute, R., Studer, L., Ferrari, D., Perrier, A.L., Lee, H., Viñuela, A., and Isacson, O. 2005. Long-term survival of dopamine neurons derived from parthenogenetic primate embryonic stem cells (Cyno-1) in rat and primate striatum. Stem Cells 23: 914-922.

Sauer, F.C. 1935. Mitosis in the neural tube. J. Comp. Neurol. 62: 377-405.

Shen, Q., Goderie, S.K., Jin, L., Karanth, N., Sun, Y., Abramova, N., Vincent, P., Pumiglia, K., and Temple, S. 2004. Endothelial 
cells stimulate self-renewal and expand neurogenesis of neural stem cells. Science 304: 1338-1340.

Shihabuddin, L.S., Horner, P.J., Ray, J., and Gage, F.H. 2000 Adult spinal cord stem cells generate neurons after transplantation in the adult dentate gyrus. J. Neurosci. 20: 8727-8735.

Shimamura, K. and Rubenstein, J.R. 1997. Inductive interactions direct early regionalization of the mouse forebrain. Development 124: 2709-2718.

Shimamura, K., Martinez, S., Puelles, L., and Rubenstein, J.L. 1997. Patterns of gene expression in the neural plate and neural tube subdivide the embryonic forebrain into transverse and longitudinal domains. Dev. Neurosci. 19: 88-96.

Shin, S., Mitalipova, M., Noggle, S., Tibbitts, D., Venable, A., Rao, R., and Stice, L. 2006. Long-term proliferation of human embryonic stem cell-derived neuroepithelial cells using defined adherent culture conditions. Stem Cells 24: 125-138.

Sibilia, M. and Wagner, E.F. 1995. Strain-dependent epithelial defects in mice lacking the EGF receptor. Science 269: 234 238.

Studer, L., Tabar, V., and McKay, R.D. 1998. Transplantation of expanded mesencephalic precursors leads to recovery in parkinsonian rats. Nat. Neurosci. 1: 290-295.

Suhonen, J.O., Peterson, D.A., Ray, J., and Gage, F.H. 1996. Differentiation of adult hippocampus-derived progenitors into olfactory neurons in vivo. Nature 383: 624-627.

Tabar, V., Panagiotakos, G., Greenberg, E.D., Chan, B.K., Sadelain, M., Gutin, P.H., and Studer, L. 2005. Migration and differentiation of neural precursors derived from human embryonic stem cells in the rat brain. Nat. Biotechnol. 23: 601-606.

Takahashi, K. and Yamanaka, S. 2006. Induction of pluripotent stem cells from mouse embryonic and adult fibroblast cultures by defined factors. Cell 126: 663-676.

Takahashi, M., Palmer, T.D., Takahashi, J., and Gage, F.H. 1998. Widespread integration and survival of adult-derived neural progenitor cells in the developing optic retina. Mol. Cell. Neurosci. 12: 340-348.

Takahashi, K., Tanabe, K., Ohnuki, M., Narita, M., Ichisaka, T., Tomoda, K., and Yamanaka, S. 2007. Induction of pluripotent stem cells from adult human fibroblasts by defined factors. Cell 131: 861-872.

Temple, S. 2001. The development of neural stem cells. Nature 414: $112-117$.

Thomson, J.A., Itskovitz-Eldor, J., Shapiro, S.S., Waknitz, M.A., Swiergiel, J.J., Marshall, V.S., and Jones, J.M. 1998. Embryonic stem cell lines derived from human blastocysts. Science $\mathbf{2 8 2}$ : 1145-1147.

Threadgill, D.W., Dlugosz, A.A., Hansen, L.A., Tennenbaum, T., Lichti, U., Yee, D., LaMantia, C., Mourton, T., Herrup, K., Harris, R.C., et al. 1995. Targeted disruption of mouse EGF receptor: Effect of genetic background on mutant phenotype. Science 269: 230-234.

Tole, S., Kaprielian, Z., Ou, S.K., and Patterson, P.H. 1995. FORSE-1: A positionally regulated epitope in the developing rat central nervous system. J. Neurosci. 15: 957-969.

Uchida, N., Buck, D.W., He, D.P., Reitsma, M.J., Masek, M., Phan, T.V., Tsukamoto, A.S., Gage, F.H., and Weissman, I.L. 2000. Direct isolation of human central nervous system stem cells. Proc. Natl. Acad. Sci. 97: 14720-14725.

Wanaka, A., Milbrandt, J., and Johnson, Jr., E.M. 1991. Expression of FGF receptor gene in rat development. Development 111: 455-468.

Watanabe, K., Kamiya, D., Nishiyama, A., Katayama, T., Nozaki, S., Kawasaki, H., Watanabe, Y., Mizuseki, K., and Sasai, Y. 2005. Directed differentiation of telencephalic precursors from embryonic stem cells. Nat. Neurosci. 8: 288-296.

Watanabe, K., Ueno, M., Kamiya, D., Nishiyama, A., Matsumura, M., Wataya, T., Takahashi, J.B., Nishikawa, S., Nishikawa, S., Muguruma, K., and Sasai, Y. 2007. A ROCK inhibitor permits survival of dissociated human embryonic stem cells. Nat. Biotechnol. 25: 681-686.

Wichterle, H., Lieberam, I., Porter, J.A., and Jessell, T.M. 2002. Directed differentiation of embryonic stem cells into motor neurons. Cell 110: 385-397.

Yamada, T., Pfaff, S.L., Edlund, T., and Jessell, T.M. 1993. Control of cell pattern in the neural tube: Motor neuron induction by diffusible factors from notochord and floor plate. Cell 73: 673686.

Yamaguchi, T.P., Harpal, K., Henkemeyer, M., and Rossant, J. 1994. $f g f r-1$ is required for embryonic growth and mesodermal patterning during mouse gastrulation. Genes Dev. 8: 3032 3044.

Yan, J., Studer, L., and McKay, R.D.G. 2001. Ascorbic acid increases the yield of dopaminergic neurons derived from basic fibroblast growth factor expanded mesencephalic precursors. $J$. Neurochem. 76: 307-311.

Yan, Y., Yang, D., Zarnowska, E.D., Du, Z., Werbel, B., Valliere, C., Pearce, R.A., Thomson, J.A., and Zhang, S.C. 2005. Directed differentiation of dopaminergic neuronal subtypes from human embryonic stem cells. Stem Cells 23: 781-790.

Ye, W.L., Shimamura, K., Rubenstein, J.R., Hynes, M.A., and Rosenthal, A. 1998. FGF and Shh signals control dopaminergic and serotonergic cell fate in the anterior neural plate. Cell 93: $755-766$.

Ying, Q.L., Stavridis, M., Griffiths, D., Li, M., and Smith, A. 2003. Conversion of embryonic stem cells into neuroectodermal precursors in adherent monoculture. Nat. Biotechnol. 21: 183-186.

Yu, J., Vodyanik, M.A., Smuga-Otto, K., Antosiewicz-Bourget, J., Frane, J.L., Tian, S., Nie, J., Jonsdottir, G.A., Ruotti, V., Stewart, R., Slukvin, I.I., and Thomson, J.A. 2007. Induced pluripotent stem cell lines derived from human somatic cells. Science 318: 1917-1920.

Zhang, S.C., Wernig, M., Duncan, I.D., Brüstle, O., and Thomson, J.A. 2001. In vitro differentiation of transplantable neural precursors from human embryonic stem cells. Nat. Biotechnol. 19: $1129-1133$. 


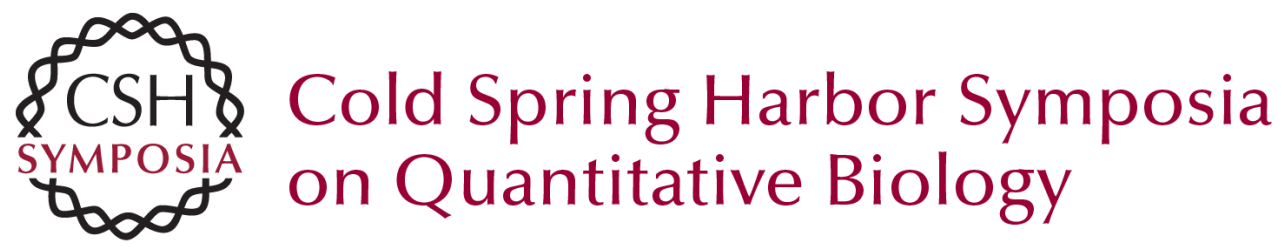

\section{Human ESC-derived Neural Rosettes and Neural Stem Cell Progression}

Y. Elkabetz and L. Studer

Cold Spring Harb Symp Quant Biol 2008 73: 377-387 originally published online February 9, 2009 Access the most recent version at doi:10.1101/sqb.2008.73.052

References This article cites 119 articles, 42 of which can be accessed free at: http://symposium.cshlp.org/content/73/377.full.html\#ref-list-1

\section{License}

Email Alerting Receive free email alerts when new articles cite this article - sign up in the box at the Service top right corner of the article or click here. 